\title{
Assessment of the global energy potential and existing areas of innovative development in the context of environmental safety
}

\author{
Arthur Gibadullin ${ }^{1, *}$, Irina Abanina ${ }^{2}$, Marina Medvedeva ${ }^{2}$, Lyudmila Shmaneva ${ }^{3}$, \\ Gulnara Alekseeva ${ }^{2}$, and Dmitry Morkovkin ${ }^{2}$ \\ ${ }^{1}$ State University of Management, Ryazan Avenue 99, 109542, Moscow, Russia \\ ${ }^{2}$ Financial University under the Government of the Russian Federation, Leningradsky Avenue 49, \\ 125993, Moscow, Russia \\ ${ }^{3}$ Moscow University of the Ministry of the Interior of the Russian Federation named after V.Y. Kikot, \\ Academician Volgin str. 12, 117437, Moscow, Russia
}

\begin{abstract}
The presented study was devoted to environmental safety in the context of the implementation of energy transfer programs. Among the main transitions, a conservative, innovative and energy transition is singled out, within the framework of which relevant measures are taken to increase the efficiency of the energy industry. The work analyzed plans for various approaches, as a result, it was concluded that in the event of an energy transition, it is planned to reduce oil and gas consumption by up to $20 \%$ and increase the consumption of renewable energy sources. The work revealed that the plans should be implemented taking into account the specifics and characteristics of the energy industries, in connection with which, a model for ensuring the energy transition containing mechanisms for decarburization, decentralization and digitalization was proposed for the Russian Federation. At the end of the study, brief conclusions are presented.
\end{abstract}

\section{Introduction}

World energy began to develop in the XV-XVIII century, when a person learned to extract process and use fuel and energy resources for his own consumption. In the XIX-XX century, energy began a large-scale transformation and development, which consisted of developing new methods for extracting energy resources, transferring them over long distances, converting them to the final product and creating an efficient consumption system [1-3]. During this period, the main types of fuel and energy resources were peat, coal, oil, gas and other extracted resources, which, as a rule, are non-renewable [4-6].

In modern times, fuel and energy resources are considered as a driver of economic development, from the point of view of replenishing the budget and providing people with all the necessary resources, on the other hand, energy consumption forms additional waste, which negatively affects the atmosphere through emissions of pollutants, and mining

*Corresponding author: 11117899@mail.ru 
violates the natural structure of soil coverings of the earth. In connection with the aggravating problems of efficient consumption and use of fuel and energy resources, humanity is thinking about reducing the consumption of such resources and replacing them with renewable resources, which practically do not affect the state of the environment [7-9].

In the 21 st century, mankind is thinking not only about the efficient use of extracted fuel and energy resources, but also about the possibility of using various types of inexhaustible resources for the production of electric and thermal energy, hot water, ensuring the operation of individual facilities in households, obtaining water resources, etc. Due to the fact that there has been a trend in the global energy sector related to the transition to new types of resources, we consider it necessary to analyze the current state of the global energy industry and possible trends in its development.

\section{Materials and methods}

The aim of this work is to assess the global energy potential and consider the conditions for the energy transition. Based on the stated goal, the following tasks were proposed:

- Analyze the global energy potential and possible options for its development;

- To propose a model for ensuring the energy transition in Russia.

The study used statistics published in open sources. The work was based on the use of scientific approaches and methods, which made it possible to reveal the goal of the study.

\section{Results}

In recent years, world energy policy has pursued a goal related to ensuring the transition from the adopted way of extraction, production and consumption of fuel and energy resources to a changed structure of resource consumption, taking into account new features of the development of mankind and national economies, this approach is called the energy transition [10].

If this goal is achieved, countries plan to reduce the use of non-renewable energy sources, for example, coal, oil and gas consumption by $15-20 \%$, and increase the consumption of biomass, waste, use of hydropower, nuclear resources, etc. Similar goals were set in almost all energy programs of national states, some of which have already achieved significant results in the transition to new types of resources, however, most countries are not able to carry out the restructuring of these types of activities [11-13].

At the same time, the energy transition should be based on the electrification of all types of activities and areas of human and industrial production, increasing the energy efficiency of production processes, the development of new technologies, including the transition to innovative and digital technologies, the creation of a distributed energy system, and cheapening of non-traditional energy, the development of energy storage technologies and hydrogen energy. The implementation of such technologies will create a working system of energy transition, which will increase not only energy efficiency, but also create an incentive for the development of national economies [14].

Of course, the energy transition cannot be carried out in all countries; this is due to the existing features of the energy industries, their scale, connection with the national economy, dependence on other areas of activity, and more. In this regard, there are three forecasts for the development of energy in the prism of the energy transition [15]:

- A conservative scenario is the preservation of established energy patterns, current state energy policy, the speed of technology development, etc.;

- An innovative scenario is the development of existing plans for the construction and operation of renewable energy sources, the transition to electric transport and increased 
energy efficiency of production. Implementation of the progressive development of technologies and the creation of conditions for the localization of production;

- The energy transition is the implementation of a decarburization policy, ensuring competition for technology and the creation of world centers for the development of new technologies.

Thus, with each transition, it is possible to achieve certain tasks that will ensure a better quality of energy, and will open up new opportunities for the economy.

Consider the structure of primary energy consumption by type of fuel in the world (figure 1) [15-16].

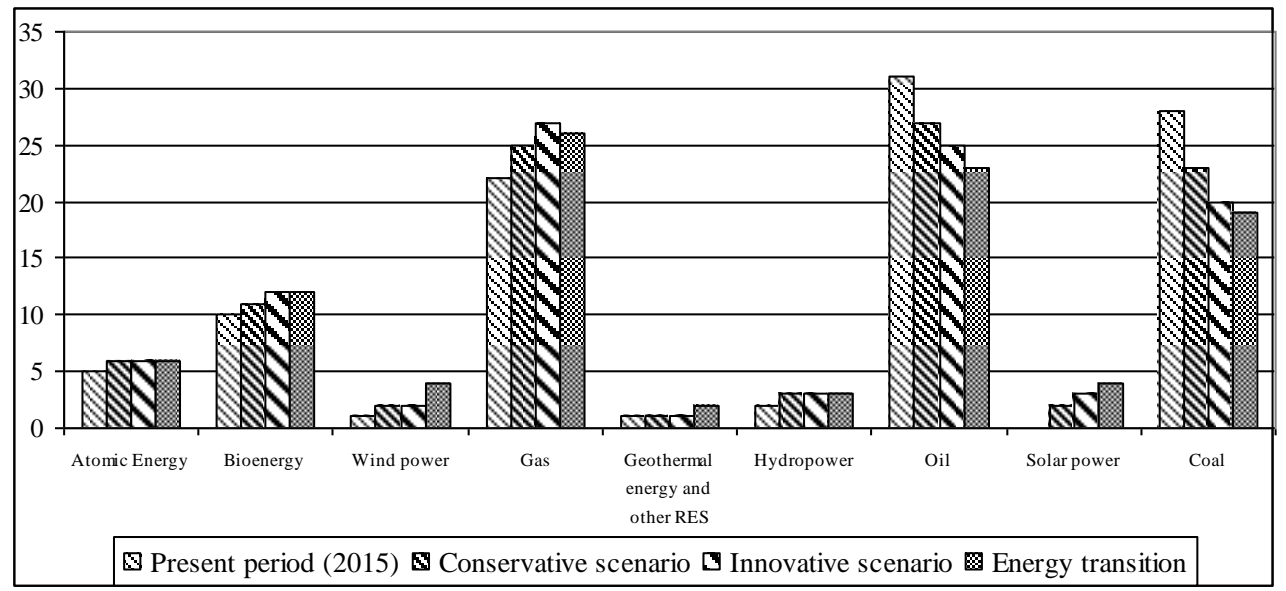

Fig 1. The structure of primary energy consumption by type of fuel in the world, as a percentage.

From the presented figure it is clear that such types of fuels as coal and oil should decrease to 20 and $25 \%$ in the global fuel and energy balance, in turn, other areas of activity and fuels should replace displaced fuels. At the same time, we see that the stronger the transition is planned, the more displacement of coal and oil and the development of new types of fuels take place.

Thus, the presented figure indicates that the global energy industry plans to make a qualitative transition to the use of new types of fuels and to ensure the development of new technologies in these areas [17].

At the same time, it seems interesting to consider the structure of primary energy consumption in the Russian Federation (figure 2) [15-16].

The figure shows that, compared with the global energy sector, Russia plans to achieve significant results during the energy transition, for example, to reduce the use of coal by half and oil by half. Of course, such an approach should provide a breakthrough development of alternative fuels, since in Russia the potential of hydropower and atomic energy is used at a high level.

Achieving such results, both for the Russian Federation and for the whole world, is possible due to the provision of technology transfer, while a similar approach should be implemented continuously and the developing countries should create continuous information flows that will allow developing countries to use them at their discretion [1820]. The Russian Federation, in this case, can act as a developer and recipient of these technologies, but if we compare the energy potential of Russia and other countries of the world, it can be said that the country is not a leader and in this case it is advisable to receive already developed technologies. 


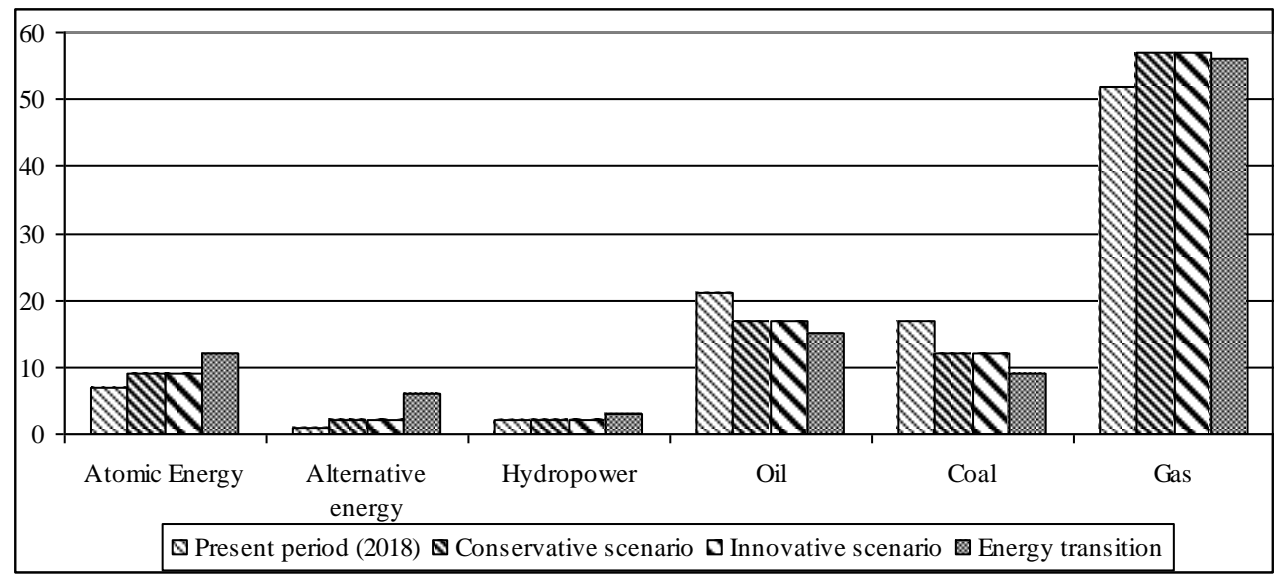

Fig. 2. The structure of primary energy consumption by type of fuel in Russia, as a percentage.

\section{Discussions}

According to researchers [15], the global energy transition should be based on three components - decarburization, decentralization and digitalization. We believe that such an approach should be transformed to the Russian Federation and present a model of energy transition.

Imagine a model for ensuring the energy transition of the Russian energy sector (figure 3) $[21-25]$.

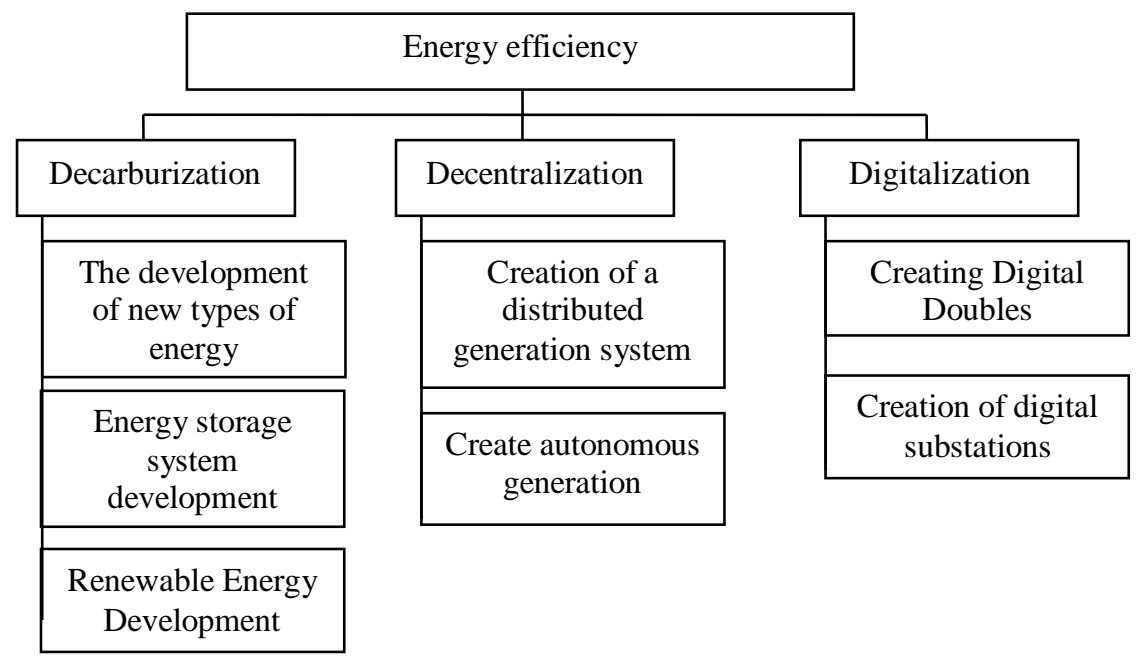

Fig. 3. Energy Transition Model in Russia.

The generated model contains the specifics of the Russian energy industry, which cannot, in a short period of time, completely rebuild and exist according to new development rules. Here we see that it is also advisable to base the model on mechanisms to eliminate the use of carbon, ensure decentralization of energy, and a gradual transition to innovative and digital technologies. 
Thus, the creation of an energy transition system is designed until 2040, of course, for such a period, it is possible to carry out a restructuring of the energy sector, but any restructuring or adjustment to new conditions should be fraught with the existing problems and capabilities of national power engineers.

\section{Conclusion}

As a part of the study, the global and Russian energy potential was analyzed and the main directions of energy development in the long term were determined. The study revealed that energy industries must make the energy transition, which can be carried out according to conservative, innovative and progressive approaches. As part of a progressive approach, it is planned to reduce oil and coal consumption by up to $20 \%$ and increase the consumption and use of unlimited natural resources. The study proved that the Russian energy industry should develop taking into account industrial characteristics, and decarburization, decentralization and digitalization should become directions. As part of the work, a model was proposed to ensure the energy transition of the Russian energy sector, taking into account decarburization, decentralization and digitalization.

\section{References}

1. V.N. Zakharov, V.Y. Linnik, Y.N. Linnik, A.B. Zhabin, Mining Informational and Analytical Bulletin, 5, 5-12 (2019) DOI: 10.25018/0236-1493-2019-05-0-5-12

2. Ir.N. Romanova, D.E. Morkovkin, V.N. Nezamaikin, A.A. Gibadullin, M.A. Ivanova, IOP Conference Series: Materials Science and Engineering, 734, 012166 (2020) DOI:10.1088/1757-899X/734/1/012166

3. I.A. Ivanova, V.N. Pulyaeva, L.V. Vlasenko, A.A. Gibadullin, M.I. Sadriddinov, Journal of Physics: Conference Series, 1399, 033038 (2019) DOI:10.1088/17426596/1399/3/033038

4. I.A. Ivanova, V.N. Pulyaeva, L.V. Vlasenko, A.A. Gibadullin, B.G. Safarov, IOP Conference Series: Earth and Environmental Science, 42,1 032039 (2020) DOI: 10.1088/1755-1315/421/3/032039

5. A.A Gibadullin, Ch.V. Kerimova, S.R. Chorshanbiev, S.V. Shmanev, Ju.A. Romanova, A.A. Sozontov, IOP Conference Series: Materials Science and Engineering, 734, 012170 (2020) DOI:10.1088/1757-899X/734/1/012170

6. Y.N. Linnik, V.Y. Linnik, A.B. Zhabin, A.V. Polyakov, Mining Informational and Analytical Bulletin, 8, 33-41 (2019) DOI: 10.25018/0236-1493-2019-08-0-33-41

7. D. Morkovkin, D. Lopatkin, M. Sadriddinov, T. Shushunova, A. Gibadullin, O Golikova, E3S Web of Conferences, 157, 04015 (2020) DOI: https://doi.org/10.1051/e3sconf/202015704015

8. F.F. Sharipov, O.A. Timofeev, Ugol' - Russian Coal Journal, 4, 68-71 (2020) DOI: http://dx.doi.org/10.18796/0041-5790-2020-4-68-71

9. S.V. Bryukhovetskaya, K.A. Artamonova, A.A. Gibadullin, S.A. Ilminskaya, Z.M. Kurbonova, IOP Conference Series: Earth and Environmental Science, 421, 042018 (2020) DOI: 10.1088/1755-1315/421/3/042018

10. V.N. Zakharov, V.Y. Linnik, Y.N. Linnik, E.A. Averin, Eurasian Mining, 1, 40-42 (2019) DOI: 10.17580/em.2019.01.10 
11. D.S. Lopatkin, T.N. Shushunova, G.E. Shaldina, A.A. Gibadullin, I.L. Smirnova, Journal of Physics: Conference Series, 1399, 033061 (2019), DOI:10.1088/17426596/1399/3/033061

12. D.I. Zimnukhova, G.A. Zubkova, D.E. Morkovkin, P.V. Stroev, A.A. Gibadullin, Journal of Physics: Conference Series, 1399, 033097 (2019), DOI:10.1088/17426596/1399/3/033097

13. A. Sozontov, M. Ivanova, A. Gibadullin, E3S Web of Conferences, 114, 01009 (2019) https://doi.org/10.1051/e3sconf/201911402002

14. P.M. Gureev, V.V. Degtyareva, I.S. Prokhorova, Advances in Intelligent Systems and Computing, 1100, 13-20 (2020) DOI: https://doi.org/10.1007/978-3-030-39319-9_2

15. Website of the Energy Research Institute of the Russian Academy of Sciences, https://www.eriras.ru

16. Russian statistical yearbook (Rosstat, Moscow, 2018)

17. V.V. Davnis, V.I. Tinyakova, V.A. Fetisov, M.A. Chervontseva, S.I. Oparina, International Journal of Recent Technology and Engineering, 8(3), 254-260 (2019) DOI: 10.35940/ijrte.C1059.1083S19

18. A. Gibadullin, V. Abramov, T. Usmanova, S. Bryukhovetskaya, A. Borisov, O. Afanasieva, E3S Web of Conferences, 164, 11018 (2020)

19. E.V. Ganina, N.M. Malyugina, R.I. Polyakova, E.A. Fedorova, O.N. Bykova, International Journal of Engineering and Advanced Technology, 9(1), 5565-5569 (2019) DOI: 10.35940/ijeat.A2128.109119

20. Website of the Ministry of Energy of the Russian Federation, www.minenergo.gov.ru

21. A. Gibadullin, V. Pulyaeva, T. Usmanova, I. Ivanova, L. Vlasenko, E3S Web of Conferences, 164, 11017 (2020)

22. S.V. Bryukhovetskaya, K.A. Artamonova, A.A. Gibadullin, S.A. Ilminskaya, Z.M. Kurbonova, IOP Conference Series: Earth and Environmental Science, 421, 042018 (2020) DOI:10.1088/1755-1315/421/4/042018

23. V.Yu. Linnik, Yu.N. Linnik, Upravlenie, 7(1) 40-49 (2019) DOI: 10.26425/2309-36332019-1-40-49

24. A.A. Gibadullin, M.I. Sadriddinov, Z.M. Kurbonova, Yu.N. Shedko, V.V. Shamraeva, IOP Conference Series: Earth and Environmental Science, 421, 032051 (2020) DOI:10.1088/1755-1315/421/3/032051

25. A.V. Kolesnikov, L.E. Zernova, V.V. Degtyareva, Iu.V. Panko, Yu.I. Sigidov, Opción, 26, 523-540 (2020) 